\title{
SOBRE VESTIMENTA E IDENTIDAD EN EL IMPERIO ROMANO: EL PROYECTO DRESSID Y SU PROYECCIÓN EN LA INVESTIGACIÓN EUROPEA
}

\author{
Michael Tellenbach ${ }^{1}$ \\ Museum Weltkulturen
}

\begin{abstract}
Resumen: En nuestro proyecto multinacional e interdisciplinar (DressID), especialistas de 35 instituciones pertenecientes a 7 países europeos investigaron durante 5 años acerca de la vestimenta en su relación con las identidades dentro del primer estado multiétnico de Europa. Hubo una amplia variación de identificaciones entre los provinciales y Roma. La sociedad romana seguía la tradición griega mediterránea: Palmira en Siria fue romana sólo en la vida oficial; en Egipto lo romano coexistía con una tradición milenaria; Hispania se identificó plenamente con Roma; Europa Central se aproximaba lentamente al modelo romano y las regiones del Noroeste anhelaron poseer un carácter mediterráneo. Los vestigios materiales de la vestimenta revelan estructuras eficaces, estandars uniformes de calidad, aproximándonos a un mundo sorprendentemente moderno.
\end{abstract}

Palabras clave: Toga, vestimenta en la antiguedad clásica, imperio multiétnico, identidades orientales y occidentales, tecnología textil, material y teñido textil, DressID.

\section{Dress and identity in the Roman Empire: DressID Project and its projection in European research}

Abstract: In our multinational and interdisciplinary project (DressID), specialists of 35 institutions in 7 European countries did research during 5 years on dress and identities in the first multi-ethnic state in Europe. There existed a broad variation in relation to identification with Rome, which followed the Greek Mediterranean tradition: Palmyra in Syria was Roman only in public life, in Roman Egypt identity coexisted with a millennial tradition, Hispania got identified with Rome, Central Europe approximated slowly and the north-western parts adopted Mediterranean identity. Existing evidence reveals efficient structures, uniform quality-standards of yarn, weaving and loom, a surprisingly modern world.

Key words: Toga, dress in classic antiquity, multi-ethnic empire, oriental and occidental identity, textile technology, textile material and dyeing, DressID.

Un homenaje a nuestra colega Carmen Alfaro constituye la oportunidad idónea para presentar en español los resultados de un proyecto internacional e interdisciplinar que logramos realizar conjuntamente gracias al apoyo de la Comisión Europea, y en el que la Profesora Alfaro participó como coorganizadora del grupo de trabajo de la Universitat de València ${ }^{2}$. Durante cinco años, instituciones de siete países europeos investigaron conjun-

Data de recepció: 15 de desembre de 2014 / Data d'acceptació: 9 de gener de 2014.

${ }^{1}$ Director del REM I Museum Weltkulturen; Segundo jefe ejecutivo de la Curt-Engelhorn-Stiftung für die Reiss-Engelhorn-Museen. Por su ayuda en la redacción del texto en español estoy agradecido a Jónatan Ortiz García, Universidad de Valencia.

${ }^{2}$ Clothing and Identities - New Perspectives on Textiles in the Roman Empire [DressID]. Ref.: 20071765/001-001 CTU COOPMU, of the European Commission (Programme Culture 2007). 
tamente sobre estos temas que están obteniendo a posteriori una gran resonancia en la investigación europea y americana. Participaron las Universidades de Copenhague, Rethymnon, Sheffield y Valencia, así como Centros de Investigación como el KIK/IRPA de Bruselas, importantes museos como el Kunsthistorisches Museum de Viena, y algunas Universidades (Colonia, Bonn, Berlin), Centros de Investigación y Museos de Alemania (Reiss-Engelhorn-Museen de Manheim). Todos ellos establecieron importantes redes de trabajo que todavía son eficaces. Carmen Alfaro estaba a cargo de las instituciones participantes de España. El proyecto se centraba en el estudio de las identidades existentes en el Imperio Romano, un tema de gran impacto debido a que aquél fue el primer estado multiétnico y multicultural de la Historia europea. Como es bien sabido, a través de la vestimenta se pueden reconocer los rasgos identitarios de una persona, puesto que a través de ella la gente presenta su estatus social y económico, su procedencia y género, su filiación política y religiosa; en otras palabras, la vestimenta refleja la identidad personal, lo que alguien quiere ser o lo que es. El punto de partida para el proyecto lo marcaba el análisis de la arqueología textil y la investigación sobre la vestimenta. Se estudiaron las fibras animales y vegetales empleadas, sus procedencias respectivas, el modo de procesamiento, las técnicas aplicadas al tejido (Anderson Strand, 2010a; Anderson Strand, 2010b; Gleba, Mannering, 2012), así como los colores con los que fue teñida la vestimenta. Entre los aspectos más tratados han figurado: la iconografía; los hallazgos textiles arqueológicos y las representaciones escultóricas para obtener información acerca de la relación entre Roma y sus provincias; las diferencias entre hombres y mujeres, niños y ancianos, la relación entre vestimenta y religión, vestimenta y disposiciones legales, comercio y producción ${ }^{3}$.

Ha sido este un proyecto que ha contado con profesionales de distintos campos de investigación: historiadores de la Antigüedad, arqueólogos y biólogos, especialistas de textiles, epigrafistas y zoólogos, historiadores del arte y físicos, especialistas en ciencias religiosas y químicos. En total cooperaron hasta ochenta y cinco científicos de treinta y cinco instituciones de diferentes países de Europa y resto del mundo. Pero lo más interesante es que, una vez terminado el proyecto los contactos entre los participantes continúan a través de las redes de intercambio cultural que se crearon. Es más, como consecuencia de nuestras labores se han institucionalizado los estudios de tecnología textil en numerosas Universidades, Museos y Centros de Investigación de gran pujanza. Propiciar este desarrollo fue una de las metas del proyecto.

Para el sociólogo, la vestimenta conforma un acceso esencial en el ámbito de la investigación de la autoconciencia, del papel a desempeñar que configura la vida de su portador y pone en realce la identidad propia. Pero si individualmente la vestimenta habla de quien la lleva, las formas de vestir de los diferentes pueblos expresan tanto la identidad colectiva como la identidad social de cada persona dentro del grupo, así como el estatus y entorno social del individuo en relación con los demás, el género y sus manifestaciones externas, la afiliación étnica, la situación en el interior de la familia y, especialmente, la condición religiosa. Las conclusiones extraídas de este tipo de documentación son más fiables que, por ejemplo, las expresiones de las fuentes literarias, de las cuales puede el

${ }^{3}$ Entre los años 2008 y 2014, han sido publicadas veintiséis monografías, más de 140 artículos y análisis de detalle, se han desarrollado simposios sobre distintos aspectos, conferencias e informes. El punto de partida lo proporcionaban la Historia de la técnica, especialmente de la tecnología textil en todos sus aspectos, y la investigación sobre la vestimenta. 
investigador apartarse con mucha mayor facilidad. El atuendo marca y delimita una realidad vital del individuo. El análisis de la indumentaria en el mundo antiguo debería, por consiguiente, proporcionar una idea certera sobre las categorías sociales y cómo tales grados estuvieron profundamente arraigados en el pensamiento de su época. Pero cabe preguntarse si todas aquellas condiciones tenían también relevancia en el ámbito romano.

En la antigua Roma el tipo de vestimenta alcanzó una importancia considerable, como demuestran elocuentemente los testimonios iconográficos. A diferencia de la situación propia de Grecia, donde la representación del cuerpo humano constituía el tema más relevante, ya fuera a través del desnudo o bien de las bellísimas transparencias que permiten apreciarlo tras los suaves vestidos representados (Richter, 1987), en la tradición romana el interés se concentraba predominantemente en la representación de la vestimenta (Zanker, 1987; Goette, 2013). Por consiguiente hay estatuas romanas "sin cuerpo", ya que les falta incluso la profundidad espacial, pero transmiten perfectamente los detalles del vestido para caracterizar a la persona que lo porta.

Pese a la posible censura social, el vestido griego disfrutó de una libertad de uso que no tuvo tan claramente el vestido romano. Desde los tiempos más antiguos Roma conoció leyes específicas en relación a la vestimenta (Houwing, 1883; Casinos, 2013), por ejemplo en lo relativo a la limitación del lujo, al uso de la toga, al empleo de determinados colores o a la reglamentación del indumento oportuno en el contexto de los rituales funerarios. Esta serie de normas, que según la tradición textual nacen a mediados del siglo VI a.C., se suceden ininterrumpidamente hasta la Antigüedad Tardía. A través de ellas emergen algunas interesantes cuestiones económicas. Se cobraban impuestos tanto por la materia prima textil como por los textiles ya manufacturados. Además, en determinados casos se protegía de esta manera la exclusividad de ciertos grupos, como ocurría con los ciudadanos romanos y el empleo de la toga. En la Antigüedad tardía las normas de singularidad para la familia imperial llegan a su máximo alcance. El emperador, su familia y su entorno palaciego componían un grupo selecto cuya vestimenta, por su estilo y coloración, gozaba de rasgos plenamente exclusivos en lo relativo al uso de la púrpura y algunos otros símbolos externos de poder (Bottiglieri, 2002; Casinos, 2013; Alfaro, 2013a). Pero habría que esperar hasta el siglo $\mathrm{V}$ para que se declarase y aceptase en Roma que la producción y propiedad de trajes de seda púrpura era un privilegio exclusivo de la corte imperial (Reinhold, 1970).

La contradicción entre la fascinación del lujo oriental y el ideal de una sencillez acorde con la tradición de los ancestros caracterizaba la identidad romana. Ambas tendencias ejercieron una persistente influencia sobre las costumbres del vestir. Ya en tiempos de la República romana hubo personajes importantes que polemizaron en contra del lujo, porque éste, según su opinión, causaba el afeminamiento de los ciudadanos. La exigencia de vivir conforme al mos maiorum, la antigua y sencilla costumbre romana, entraba en colisión con la tendencia de los romanos a la exageración mediante el uso de indumentos suntuosos. Esta tendencia resurgía siempre en Roma propiciada por el esplendor y el refinamiento de las regiones orientales conquistadas, que atesoraban antiguas tradiciones. Frente a sus súbditos próximo-orientales el Emperador romano debía presentarse de acuerdo a su rango luciendo una indumentaria vistosa, pues una sencilla toga de lana hubiera sido totalmente inadecuada.

Según las fuentes antiguas, las costumbres de intercambiar regalos, aun en provincias pobres como Bretaña, y el empleo de ofrendas funerarias lujosas, de la cuales tenemos información gracias a las excavaciones arqueológicas (por ejemplo, en Tréveris), dejan entre- 
ver que la vestimenta de alta calidad estaba difundida mucho más de lo que cabía pensar, tomando en consideración las estimaciones sobre la estructura de la propiedad y la distribución de la riqueza en el Imperio Romano. Tejidos de seda púrpura con hilos de oro entretejidos fueron en sí ya un símbolo de lujo. Frente a la habitual valoración sobre la eficacia lograda por las disposiciones legales tendentes a limitar esa vestimenta de lujo, descubrimos que su utilización estuvo ampliamente difundida en Roma y su imperio. Se ha supuesto incluso que los desequilibrios en la balanza de pagos romana obedecieron en buena medida a la salida de numerario para la adquisición de costosas telas de lujo, comercializadas desde el lejano oriente por la famosa Ruta de la Seda (Plin., NH XII, 41 y 84).

Ahora bien, ¿cómo se vestía el ciudadano romano corriente y cómo se diferenciaba su vestimenta de las prendas usadas por los habitantes de Europa Central, del Oriente, de Egipto y de cualquier otra región del imperio? La toga del ciudadano libre romano fue la única forma de vestimenta masculina usada desde los comienzos en Italia y no asumida por otras culturas. Plinio el Viejo ya había indicado que la toga tenía su origen en la tebenna etrusca. En este contexto tiene importancia uno de los hallazgos funerarios del siglo VII a.C. de la necrópolis etrusca temprana de Verucchio, cerca de Rimini (Stauffer, 2002 y 2004). Basándonos en el inventario de la tumba, en un trono con decoración figurada, en las fíbulas de oro y en el hacha ceremonial, podríamos identificar la tebenna como una vestimenta del soberano. El detallado análisis en el contexto de los trabajos del DressID revelaba que había sido una vestimenta roja purpúrea, con cuentas de vidrio y ámbar formando un patrón decorativo: la tebenna no sería en origen sino una insignia real. Ya en el siglo VI a.C. ciertas pinturas etruscas -por ejemplo en las construcciones funerarias de Cerveteri y Tarquinia- ilustran cómo se vestía la tebenna (von Hase, 2013): pasando bajo la axila derecha, con ambos extremos sobre el hombro izquierdo y cayendo largamente hacia el pecho y la espalda, igual que lo hará la toga. Será 400 años más tarde cuando se encuentre en las tumbas etruscas tardías y en las esculturas de bulto redondo la forma de vestimenta conocida como toga, la cual es mucho más grande que la tebenna y envuelve todo el cuerpo (Bonfante, 2003). En los siglos posteriores la toga se diseñará cada vez con mayor abundancia de tejido. La forma de segmento de círculo es idéntica en la toga y la tebenna, aunque el tamaño de la primera hace que se tenga que colocar sobre el cuerpo a base de organizar un paquete de pliegues a la altura del hombro izquierdo. La toga se llevaba de forma muy cuidadosa, pues en la antigua Roma no se portaba simplemente la vestimenta, sino que con ella más bien se adornaba el cuerpo. El togatus necesitaba ayuda a la hora de colocarse este grande y pesado indumento encima de la túnica. Un movimiento brusco podía desarreglar la prenda, por lo que el togatus estaba obligado a moverse siempre con dignidad y de forma mesurada. Por eso fue un elemento característico de la identidad romana de la clase alta dedicada a la política (Gabelmann, 1985; Goette, 1989; Goette, 2013).

Cuando los ciudadanos romanos ejercían un cargo oficial debían portar la toga. En cambio, la imagen del emperador no se limitaba al simple esquema del togatus. En ciertas ocasiones se le personificaba como un hombre piadoso, celebrando el ritual de sacrificio en su función de pontifex maximus (Fernández Nieto y Molina Gómez, 2012). Entonces portaba la vestimenta oficial para dicho contexto, y un borde de la toga cubría la parte trasera de la cabeza a modo de velo. En la decoración de su armadura, a caballo o de pie, el césar retoma la tradición de los soberanos helenísticos que arranca en Alejandro Magno. Los relieves escultóricos de la armadura ilustran sus hazañas heroicas y su programa polí- 
tico. Una tercera variante es la del emperador divinizado. Entonces lo sublime es su cuerpo desnudo.

La mujer libre romana, después de los ritos de transición de la boda, durante los cuales la esposa vestía la tunica recta con cinturón de lana y el velo, preferiblemente tejidos por ella misma, se ponía la stola. Tal fue la costumbre por lo menos durante la temprana época imperial. Se trataba de una prenda de vestir tan difícil de portar como la toga. $\mathrm{Su}$ nueva identidad de matrona adquiría su expresión mediante aquella pesada prenda, un vestido largo que llegaba hasta los tobillos y en cuyo borde inferior presentaba una banda de color púrpura. Cuando se movía en público la mujer llevaba encima un gran manto denominado palla (prenda correspondiente al himation griego), con el que se podía también cubrir la cabeza.

Como ocurría con la toga, aparte del tipo puramente romano de la mujer con stola, el cual desaparece ya desde finales del siglo primero después de Cristo, no pueden señalarse discrepancias importantes entre la vestimenta griega y la romana. Por lo menos en las esculturas no existieron diferencias. Solamente en la forma de uso de la vestimenta y del velo entre las mujeres griegas se vislumbran algunas desemejanzas.

Un mérito sobresaliente de Roma generalmente reconocido es la habilidad con la que desarrolló relaciones con la civilización urbana del Oriente helenístico. Aun cuando los orientales habían sido vencidos y dominados política y militarmente, siempre fueron admirados entre los romanos como un ejemplo de cultura. Ello no quiere decir, sin embargo, que Roma se hubiera convertido en una dependencia cultural de Grecia. Al contrario, finalmente los griegos reconocieron a los emperadores romanos como los verdaderos herederos de Alejandro Magno. En los siglos anteriores a Cristo, los griegos habían helenizado gran parte de los pueblos de Asia Menor y de los Balcanes. Estas gentes fueron abandonando - por lo menos en la representación pública- sus trajes típicos, mayoritariamente en favor de la vestimenta helenística mediterránea. En todo el ámbito griego fueron representados los difuntos vestidos con chiton e himation, es decir, vestidos como griegos. Y también Roma se había adaptado a la moda de la vieja koiné griega. El estilo de vestir mediterráneo greco-romano es una herencia helenística, caracterizado porque la prenda de vestir se halla puesta alrededor del cuerpo. Caía en pliegues y transmitía no sólo intensidad dinámica, sino también elegancia y sublimidad (Tzachili, 2013).

Muchas de las técnicas textiles especiales no llegaban a Roma desde el oriente, sino que derivaban de la tradición helenística de Asia Menor, como por ejemplo la producción de hilos de oro. Muchas formas de vestimenta de los griegos fueron adoptadas en Roma: la túnica correspondía al chiton, el palio al himation, etc. Sin embargo, los griegos seguían utilizando la tebenna en lugar de la toga y luego llamando a la toga tebenna, pues este indumento oficial, símbolo del ciudadano libre de Roma, se consideraba una provocación extranjera. Cuando finalmente la capital fue trasladada de Roma a Bizancio la toga, paralelamente, ya no estaba en uso.

Las bases helenísticas de la identidad mediterránea llevaron a homogeneizar y hacer prevalecer la vestimenta romana y griega hasta una buena parte de Asia Menor y del Cercano Oriente. Sin embargo, existe el caso del oasis de Palmira, en donde se fusionaron el mundo mediterráneo y el asiático del reino parto (Schmidt-Colinet, 1996; Schmidt-Colinet, Stauffer, Al-As'ad, 2000; Schmidt-Colinet, 2009); la ciudad estaba situada en el extremo occidental de la ruta de la seda. Hasta allí llegaban las caravanas desde el Sur y Oriente de Asia. Existe un amplio conocimiento de cómo se mostraban las familias diri- 
gentes de este oasis, porque aparte de las pinturas y hallazgos de torres funerarias del s. II d.C. se conservaron hipogeos del s. III d.C. donde figura el señor de la tumba, rodeado de sus familiares. Las esculturas están trabajadas con mucho detalle en la suave roca calcárea local. Las representaciones de las vestimentas que aparecen en ellas pueden compararse perfectamente con los hallazgos textiles del yacimiento. Cada una de las personas está representada ocupándose de diferentes funciones y con distintas combinaciones de vestimenta. Se ven prendas de vestir sueltas, otras decoradas con vistosos colores rojos y blancos en escenas de sacrificio. Hay indumentos de distintas tonalidades, hechos a la medida, como aquellos lucidos por los partos, jinetes nómadas que los vestían durante sus opulentas fiestas. Gracias a sus investigaciones sistemáticas sobre el significado de los elementos de adorno textil (clavi, etc.) los especialistas han conseguido grandes avances. Cada vez es más evidente que no sólo se puede relacionar estilos de vestir determinados a partir de contextos tanto privados como oficiales, sino que los elementos decorativos, las formas de ponerse ciertas prendas de vestir y la disposición de la vestimenta expresan identidades sociales y atribuciones concretas como son el rango familiar, la filiación a un clan y la profesión.

La inmensa riqueza de Palmira se refleja no sólo en el esplendor de sus templos y de su arquitectura funeraria conservados todavía hoy, sino también en los bienes del comercio mismo, hallados durante las excavaciones arqueológicas (Stauffer, 2007a), como por ejemplo la seda de China, los textiles de algodón de la India, la lana de las famosas cabras de Cachemira en el Asia Central, o la variedad de tintes de la India y del Sureste Asiático, del este de Anatolia y, probablemente también, del golfo Pérsico. Los análisis de colorantes revelan que las sedas con decoración bordada y entretejida, incluso las telas de seda de la corte real de China, llegaron sin problemas hasta Palmira (Stauffer, 2007b), pero también las materias primas de alta calidad. Palmira no fue solamente una metrópolis comercial, puesto que también contó con lugares de procesamiento de materiales exóticos en los que se combinaba seda con lana, se entretejían bandas decorativas de color púrpura, etc.

El famoso Periplus Maris Erythraei fue una fuente histórica importante para documentar el comercio de larga distancia en época romana. Este texto describe los intercambios con la India a través de los contactos marítimos facilitados por el monzón. El punto de partida eran los puertos egipcios del Mar Rojo. La ruta de comercio transcurría por el océano Índico hasta la costa Malabar, o bien por el paso de Khaiber del Hindukusch hasta los oasis de Asia Central y China, evitando el reino Parto. El comercio con la India fue altamente especulativo; tal vez por ello fue prohibido a los senadores romanos. Aparte de las especias, las telas de algodón fueron las más interesantes importaciones de la India (Albaladejo, 2011). En contraste con este material la seda de Asia oriental se extendía rápidamente en todo el Imperio Romano, como constatan varias ricas tumbas con brocados de oro halladas incluso en las islas Británicas.

Palmira fue destruida a causa de un conflicto con Roma, no por tratar de independizarse, sino porque ella misma aspiraba a ser el centro. Zenobia, la soberana de Palmira, declaró a su hijo emperador, y en consecuencia la ciudad fue arrasada.

En el Egipto romano la vestimenta mediterránea de tradición helenística fue ampliamente difundida. Gracias a las costumbres funerarias y a las condiciones de conservación ideales, disponemos de una gran cantidad de textiles originarios del país del Nilo. Transmiten una viva imagen de la apariencia y calidad de los vestidos romanos de lino y lana, que en otras regiones están representados sólo por pequeños fragmentos y, por vía indirecta, a través de pinturas y esculturas. Adicionalmente el corpus considerable de retratos de 
momias del Fayum (Parlasca, 1966; Borg, 1996) presenta excelentes informaciones de detalle sobre las formas del vestido y de la joyería, así como del peinado y maquillaje. La gran cantidad de vestidos originales e ilustraciones a color de alta calidad permiten comparaciones a gran escala e invitan a realizar también aquí las investigaciones comenzadas ya en Palmira sobre el significado de los elementos de la decoración textil. Estos elementos de la vestimenta de Palmira, de tradición parta, pueden también observarse en Siria y en Egipto. En un caso cabe incluso asociarlos a tropas romanas procedentes de aquella ciudad, mediante la repetición de los signos distintivos de los oficiales. En telas egipcias se encuentran además motivos de zarcillo hechos con hilos de lana, tal como se conocen en Palmira. Parece que el intercambio de motivos tuvo lugar entre talleres textiles sirios y egipcios a través de muestrarios y de los propios textiles.

Hay una gran cantidad de información sobre la vestimenta romana procedente única y exclusivamente de la provincia de Egipto, porque sólo allí existen las fuentes correspondientes. Gracias a los abundantes textos de Egipto podemos hacernos una idea de la calidad y cantidad de la vestimenta femenina en un hogar particular, por ejemplo gracias a un papiro con la denuncia de una dama de un pueblo rico en el oasis Fayum por robo y asesinato (Römer, 2013): aquella mujer denuncia la desaparición de diecinueve vestidos -algo menos de un tercio de los mismos era de color-, así como de diez abrigos y capas mayoritariamente de color, además de algunas mantas y sábanas. El hecho de que la pérdida de muebles de la casa, de una gran cantidad de joyas y de dinero en efectivo se mencione sólo al final, suministra un interesante indicio acerca del gran valor concedido a estos textiles.

Poseen suma importancia las fuentes egipcias en lo que se refiere a los colores, dado que éstos no se pueden deducir tan fácilmente de las esculturas romanas, pues su coloración se perdió casi por completo. En el transcurso de generaciones vemos que desde el Alto Imperio temprano se prefirieron diferentes colores y combinaciones en los trajes y abrigos, así como diferentes anchuras para las bandas decorativas de las túnicas. Las mortajas pintadas de Egipto nos trasmiten una magnífica idea de la vestimenta mediterránea de época romana. Se representan hombres en túnica blanca con clavi oscuros y portando mantos, mujeres en túnicas de colores variados y chales que concuerdan con los colores respectivos. A veces sus túnicas están ceñidas bajo el pecho con la ayuda de un cinturón. La dalmatica, una forma especial de túnica, provista con anchas bandas decorativas que contienen dibujos de bandas trenzadas o formas vegetales, parece completar el típico repertorio de la indumentaria femenina a partir del s. II d.C. A este conjunto pertenece el gorro hecho con la técnica denominada Sprang, además de los calcetines con bifurcación en la punta, dispuestos para que la correa de la sandalia pase entre el dedo gordo y el segundo dedo del pie. Solamente gracias a las fuentes escritas del Egipto tardío tenemos conocimiento de las condiciones de producción y de los detalles de la organización de la artesanía textil en el Egipto romano; en este terreno debemos destacar los contratos de aprendizaje estandarizados para artesanos femeninos y masculinos, en los cuales estaba claramente determinado el tiempo de formación profesional, el pago, el alojamiento y las vacaciones reglamentadas de los trabajadores, así como un examen final (Wipszycka, 1965; Alfaro, 1999; Droß-Krüpe, 2011). En el Egipto romano se encuentran varias formas de organización del trabajo textil que son sorprendentemente modernas, formas que son independientes de aquellas propias del ámbito familiar. Es cierto que tales estructuras fueron abandonadas al final de la Antigüedad; pero constituyeron, sin embargo, una parte de la identidad romana. Sorprende la organización tan racional, con su tendencia a optimizar 
la producción tal como se manifiesta por la divulgación sucesiva de instrumentos técnicamente mejorados; en esa línea ocupa un lugar preeminente el telar horizontal elevado egipcio, el cual es mucho más eficaz que los anteriores y que fue introducido, muy posiblemente, en todo el Imperio hasta el Noroeste de Europa, las costas del Mar Negro o la Península Ibérica. Este instrumento era muy apropiado para los nuevos estándares de la producción textil.

Parece que los egipcios aceptaron muchas estructuras romanas de manera natural. El helenismo ya les había influenciado profundamente, a pesar de su continuidad históricocultural de la sociedad del Nilo durante 3.000 años. Es complicado saber qué significado exacto tendría todo esto para la identidad de los egipcios. Esta particularidad cultural se hace palpable en una mortaja pintada conservada en el Museo Egipcio de Berlín: un hombre con vestimenta mediterránea, con un peinado de estilo antoniniano, figura flanqueado por la deidad psicopompa (Anubis) y por el dios de los muertos (Osiris). Observando el cuadro con más detalle reconocemos que el trasfondo del lienzo está subdividido en estanterías, en las cuales se hallan representados los pasos sucesivos de la momificación egipcia mediante ilustraciones y pasajes escritos. Es como si en este caso el personaje mediterráneo estuviese sobrepuesto a la tradición egipcia, sin que ésta hubiera sido borrada.

El extremo occidental del imperio se presenta totalmente diferente. A pesar de que la conquista romana de la Península Ibérica fue resultado de ásperas guerras durante dos siglos y de que hubo una rica tradición en lo referente al vestido que se puede seguir en la iconografía ibérica y celtibérica, la Iberia romana es la única región del Imperio en la que no se encuentra ninguna representación de los habitantes vestidos todavía con sus trajes autóctonos. Aquí se verifica claramente la hipótesis de que la vestimenta expresa la identidad, pues el atuendo exclusivamente romano debe interpretarse de hecho como una fuerte identificación de los habitantes de Iberia con Roma. No es casualidad que Trajano y Adriano, los primeros emperadores que no provenían de Roma, fueran oriundos de las Hispaniae. Y aun después, emperadores relevantes como Marco Aurelio y Teodosio tendrían su origen familiar en España. Una señal de esta proximidad interna entre los pueblos ibéricos y Roma parece ser también el desarrollo cultural posterior, por ejemplo en el idioma -en ciertos aspectos, el español está muy cercanamente emparentado con el latín, casi como el italiano.

Otro de los factores que evidentemente facilitaron la aceptación de la identidad romana es el hecho de que la Península Ibérica -a diferencia de Europa Central- había sido parte de la cultura mediterránea durante largo tiempo. Encontramos esculturas de los siglos IV y III a.C. que nos proporcionan una visión elocuente de la vestimenta y de los modelos de autorrepresentación en época prerromana. Uno de los hallazgos más importantes fue el de la llamada Dama de Baza (Presedo Velo, 1972; AAVV, 2010; Demant, 2014). Dentro del grupo de figuras femeninas entronizadas y ricamente adornadas que conservamos en el Mediterráneo occidental, la Dama de Baza es seguramente la pieza con mayor número de detalles; fue una versión ibérica de estatuas mediterráneas similares, destinadas todas ellas a contextos religioso-funerarios. En este caso, la mujer viste con una túnica de manga larga que cubre otras prendas parecidas, quizás faldas, de diferente longitud, logrando una bella imagen escalonada del vestido. Sobre estas túnicas, la Dama de Baza luce un manto que cubre asimismo la cabeza. La importancia atribuida a esta prenda de vestir expresa diferencias sustanciales con la tradición griega contemporánea. Bajo la dirección de Carmen Alfaro fue reconstruido el vestuario de la Dama de Baza teniendo en 
cuenta parámetros histórico-artísticos (Alfaro, 2013b; Alfaro, en prensa). El manto se interpretó con la forma de un segmento de círculo, muy semejante a la ofrecida por los mantos hallados en una tumba del cementerio de Verucchio, a los que antes nos referíamos; esta prenda debió llevarse con la parte redondeada apoyada en la cabeza. Lá unica forma de lograr con las técnicas de aquella época un borde cuadriculado del manto y de la túnica superior, tal como aparece en la escultura, era tejerlo con ayuda de un pequeño telar de placas (Demant, 2011).

Junto a las grandes esculturas, los pequeños bronces votivos procedentes de los santuarios de Andalucía, muchos de ellos de la región jienense, han contribuido positivamente para la comprensión del vestido ibérico y de su simbolismo socio-religioso (Rueda, 2008, 2011, 2013 y en prensa). Se trata de una gran variedad de representaciones masculinas y femeninas, que muestran la vestimenta propia de las diferentes edades de la vida y de la distinta posición social.

En el noreste peninsular, numerosas estatuas de guerreros de la cultura Castreña documentan una concepción de la escultura que contrasta vigorosamente frente a otras tradiciones hispanas prerromanas: se trata de figuras relativamente abstractas que contienen representaciones de armas y decoraciones y llevan vestimentas consistentes en camisas de manga corta y faldas de diferentes formatos (García Fernández-Albalat, 2013).

Esta gran variedad de los trajes se pierde con la romanización, al menos a partir de la imagen que ofrecen las esculturas conservadas. Desde la época de Augusto hasta la Antigüedad Tardía se repiten las esculturas de bulto redondo y los relieves funerarios que representan a los iberos romanizados. Hispania era un importante centro textil, y sus productos eran altamente apreciados en Roma, tanto las materias primas como los indumentos manufacturados (Alfaro, 1997). Las fuentes escritas antiguas nos cuentan la amplitud del cultivo de lino, así como su extendido uso para la elaboración de hilos y textiles (Alfaro, 2011). La calidad exquisita del lino blanco y radiante fue muy codiciada por parte de los romanos. Asimismo tenía un alto significado la calidad del color de otros productos, como por ejemplo la lana negra ibérica o la rojiza de la Hispania Baetica, cuyo uso reducía el gasto en el teñido.

La Europa central romana se diferencia marcadamente de la región Hispana. En las estelas funerarias del Noricum, al oriente de los Alpes y en la parte del Danubio panónico, se representa con mucho detalle el atuendo de tradición prerromana, en especial el traje femenino. Saltan a la vista los tocados elaborados y las túnicas sobrepuestas (PasztókaiSzeöke, 2011). Según las imágenes conservadas en algunas magníficas situlae, típicas de la zona, hombres y mujeres disponían de vestimentas muy semejantes. El único indicio para diferenciar mujeres y hombres son los gorros y los velos. Sin embargo, hay también representaciones de pantalones y caftanes.

En Panonia el conjunto del vestido celta de época tardía muestra dos túnicas, un manto y un sombrero o gorro. Las formas concretas de este conjunto varían según la región y la edad del difunto; la mujer destaca por asumir el papel de conservar puras las tradiciones locales, circunstancia que nos llama la atención. Gracias a las inscripciones resulta sencillo relacionar los detalles de los trajes con las etnias respectivas. Sorprendentemente, mujeres que pertenecieron a tribus en principio insurrectas y reasentadas por la fuerza están representadas a menudo, apareciendo ricamente adornadas; en cambio los hombres no lucen traje local, sino que figuran con vestidos de ciudadano romano o con uniforme de soldados. El cuadro general aconseja deducir que no se segregó o minusvaloró negativa- 
mente a las etnias insurrectas o extrañas a la romanidad. De hecho, la costumbre romana de erigir estelas funerarias con la imagen del difunto dio lugar a que se conservaran bastantes datos de la identidad local a través de la vestimenta. El análisis de algunos hallazgos textiles ha permitido asimismo valorar algunos indicios del proceso de romanización en la producción y calidad del hilo, del tejido y de la vestimenta, como es el caso de los textiles de la tumba real de Poprad (Belanová y Pieta, 2007).

En las minas de sal de Hallstatt se hallaron fragmentos textiles de la época prerromana conservados magníficamente. Muestran franjas polícromas con diseños muy variados y podemos atestiguar el uso de muy diferentes tipos de tintes de origen vegetal, que en esta ocasión han podido analizarse (Grömer, 2010). En los siglos del imperio se observa una estandarización cada vez mayor, que contrasta con las primitivas tradiciones celtas. Al parecer, la nueva tendencia irradia desde Roma, primero a través de las culturas vecinas, también de raigambre céltica, y más tarde directamente desde Roma; se distingue por su renuncia a la decoración, por la simplificación de la forma de tejer y la estandarización del grosor de los hilos, que son torcidos cada vez más finamente. Escasa y excepcionalmente se aplica la decoración hecha con hilos de oro y seda. La tendencia hacia la uniformidad de los productos, la manipulación racional de la producción y la introducción de estándares de calidad constituyen el balance de la identidad romana de esta parte del centro de Europa.

En la zona de las Galias, en las provincias del Rin y en Britania la población local erigía monumentos funerarios con la representación de los difuntos siguiendo las costumbres romanas; en especial las mujeres figuraron en la época de los Flavios vestidas en sus trajes tradicionales. Se trata de testimonios únicos, porque sólo a través de esas estelas puede deducirse cómo se presentaban las diferentes etnias (Esperandieu, 1907-1938). En algunos casos existen incluso altares con figuras de deidades ataviadas con las modalidades indígenas del vestido. En la región de Colonia el traje usual de la mujer ubia constaba de una túnica interior, un vestido largo sostenido con un cinturón bajo el pecho y una gran fíbula (Carroll, 2010). Ciertos detalles concretos, como un gorro grande globular y collares con un pendiente en forma de medialuna son muy típicos de estos territorios, en donde la costumbre mediterránea de construir monumentos para los dioses se aplica al panteón local, concretamente a las deidades femeninas de los ubios, las llamadas "Matronas". Este traje local fue sustituido en el siglo II d.C. por uno sin fíbulas, el llamado "conjunto galo" (Rothe, 2009).

La desaparición de los numerosos trajes locales del Noroeste del imperio en el siglo II d.C. y la aparición del "conjunto galo" demuestran que en esta parte del Imperio se ha desarrollado una identidad común propia. Fue la consecuencia de un continuo proceso de integración con Roma; sin duda, es evidente el contraste con la tradición de la región del Danubio. Sintomáticamente el Imperio Romano se convirtió en un mito sólo en la región del Rhin y de Galia, donde se fundó de nuevo siglos más tarde "El Sacro Imperio Romano".

En el campamento militar de Maguncia (zona del Rin) se rescataron en los siglos XIX y XX importantes hallazgos textiles. Se trata del conjunto más grande de este tipo en Europa Central (Böhme-Schönberger, Mitschke, 2005). Investigaciones muy atentas sobre estos textiles, realizadas en el contexto del proyecto DressID, han proporcionado información técnica de primera importancia. Algunos de estos tejidos sirvieron para acolchar corazas y cascos, para embalaje, etc. Debido a la calidad técnica y a la decoración que conservan la mayoría de ellos puede identificarse como restos de vestimenta reutilizados. El análisis de las telas nos provee además de indicios importantes sobre los estándares de calidad de la vestimenta de las tropas romanas. 
Nos podemos hacer una idea más precisa de la indumentaria de los soldados romanos gracias al análisis de hallazgos encontrados en el suelo pantanoso del castellum de Vindolanda, en el muro de Adriano. Se trata de cientos de fragmentos textiles y de tablillas de madera para escribir (Bowman y Thomas, 1994; Bowman, 2003; Bowman, Thomas y Adams, 2003; Birley, 2009a y 2009b; Bowman, Thomas y Tomlin, 2010). Estas últimas tenían también anotaciones relacionadas con la producción textil; los hallazgos datan de la transición del siglo I al II d.C. Tales vestigios han sido examinados desde el ángulo de las cuestiones tecnológicas, económicas y sociológicas. Los términos para designar los diferentes tipos de manufacturas se analizaron ya hace tiempo y describen producciones específicas (Wild, 2011). A través del estudio filológico pudieron reseñarse las diferentes producciones de tejidos propios para la vestimenta, distinguiéndolos del material destinado para accesorios y enseres domésticos, de modo que todos los fragmentos textiles de túnicas y mantos conservados se han puesto en relación con cuanto sabemos sobre los restantes materiales que existieron. Hemos reunido informaciones, gracias a los textos en las tablillas, sobre la vestimenta festiva y el estilo suntuoso que acostumbraba exhibir el comandante del castellum y su familia en el praetorium, así como detalles referentes al protocolo para invitaciones, fiestas y vestidos de noche; todo ello parece reflejar marcadas diferencias de clase entre su estilo de vida y el de un simple soldado, que habitaba en alojamientos estrechos. Sin embargo, el análisis de los hallazgos textiles arqueológicos abona una idea que nos impide generalizar esta impresión, puesto que habla en favor de que una característica general del simple soldado romano fue la de disponer de una vestimenta sólida, de buena calidad (Speidel, 2009; Hoss, 2010). Si éste es el caso global del ejército, deberíamos probablemente revisar nuestro concepto sobre la relación entre el ejército y la sociedad romana, permitiéndonos abrir nuevas vías en el ámbito de la autoconciencia y la identidad.

Como es sabido, el Imperio Romano mantuvo un intercambio intenso con las regiones de fuera de sus fronteras. En el caso de la vestimenta las interrelaciones entre Roma y los "bárbaros" pueden analizarse de modo muy satisfactorio en el Norte de Europa, porque los pantanos y suelos húmedos de estas latitudes ofrecieron condiciones de conservación óptimas para los tejidos, siempre y cuando éstos hubieran sido fabricados con fibras de origen animal. Las investigaciones sistemáticas de los abundantes hallazgos de vestimentas en la Escandinavia prerromana revelan que se cortaba y cosía sólo una parte de la ropa, en concreto aquella que fue hecha con pieles y cuero, mas no la vestimenta de origen textil. Tanto en Escandinavia como en la región mediterránea las prendas salían del telar ya confeccionadas. Parece que los gorros hechos con la técnica conocida como Sprang, o sombreros de piel, constituían el elemento que marcaba la diferencia entre los trajes femeninos y los masculinos. Las fíbulas sobre el hombro sostenían mantos, así como grandes telas a manera de capas. Pero eran también frecuentes los vestidos con tirantes. Las capas de piel en región tan fría eran una solución necesaria.

A partir de la época de los primeros contactos aparecen en el Norte diferentes hallazgos preciosos de importación romana, así como vestidos diferenciados según el género de los destinatarios. Sorprendentemente, en la época de la influencia romana se encuentran por primera vez pantalones, pero sólo al sur de Escandinavia y en el Norte de Alemania. Hasta ahora se había pensado que los pantalones habrían llegado a Roma desde el Norte, aunque tal vez no fuera así. Es un tema que exige ser examinado en profundidad.

Sin embargo, parece que las influencias procedentes del Sur no favorecieron la tendencia a copiar o imitar los modelos de vestido. Así se deduce por las nuevas investiga- 
ciones y revisiones sobre los antiguos hallazgos procedentes de Thorsberg y de otros tres sitios importantes del Norte de Europa. Allí se extrajeron más de mil armas e instrumentos preciosos, posiblemente consagrados como un botín de guerra (Hald y Olsen, 1980). Se conservan dos pantalones con calcetines añadidos, una túnica de manga larga y varios mantos con una franja ancha tejida en un telar de placas. En todos los hallazgos resalta mucho no sólo la calidad extraordinaria de los tejidos, sino también la uniformidad y densidad de los hilos, así como la calidad de los tintes empleados. El análisis comparado de las características técnicas (hilo, manufactura textil, bordes) nos revela que los textiles fueron producidos localmente. Las primeras isotopías de estroncio confirman este resultado (von Carnap-Bornheim, Nosch, Grupe, Mekota, Schweissing, 2007; Frei, Frei, Mannering, Gleba, Nosch, Lyngstrøm, 2009).

Las élites nacionales en el Norte de Europa usaban textiles locales, y si bien es cierto que llevaban armas romanas, éstas estaban decoradas con símbolos distintivos germánicos. Muchos bienes de lujo romanos depositados en tumbas ricas de la época imperial de la región del Mar Báltico demuestran que las relaciones con Roma implicaron prestigio para las élites nórdicas. Sin embargo, debido a su identidad permanecieron vinculados con el mundo simbólico local y también con elementos de vestir no romanos.

Gracias a un nuevo análisis detallado de la vestimenta de la momia del pantano llamada "Hombre de Obenaltendorf" resulta evidente que también gente con ropa mediterránea viajaba por el Norte (Möller-Wiering, 2007); la momia fue descubierta en el año 1895. El análisis del tipo de torsión del hilo, de la unión de las telas, de los bordes tejidos y de la decoración de los clavi son elementos que demuestran que la indumentaria era mediterránea. Sólo la gran estatura, el hecho de ser pelirrojo, sus zapatos sin duda germánicos, dos pendientes tipo Berlock y la ausencia de cualquier indicio de un cinturón hace suponer que no era romano ni tampoco un soldado. Otras dos momias semejantes demuestran que el hombre de Obenaltendorf no fue un caso excepcional.

El análisis interdisciplinar de las múltiples y variadas evidencias que tenemos acerca de las formas de vestirse de los pueblos del Imperio Romano y de las identidades que encierran nos revela una marcada variación regional en cuanto a la identificación con el Imperio Romano. La vestimenta romana no indicaba filiación étnica, sino estatus legal. No hay indicio alguno de conflictos étnicos dentro de este dominio multiétnico. Roma seguía las tradiciones mediterráneas de vestir; éstas y las técnicas de su producción llegaron a todas las partes del Imperio. Durante los siglos subsiguientes fueron adoptadas con ligeras variaciones por todos los pueblos que lo integraban. Ahora bien, a pesar del gran número de especialistas implicados y del carácter internacional e interdisciplinario de nuestro proyecto, que permitió ampliar considerablemente la base de los datos para el análisis, los resultados no dejan de tener carácter preliminar. Evidencias nuevas, obtenidas en investigaciones futuras, permitirán sin duda ulteriores resultados e interpretaciones.

\section{BIBLIOGRAFÍA}

ALBALADEJO, M. (2011): "El color en el vestido, símbolo de identidad en el mundo antiguo: el paradigma indio", Herakleion, 4, 47-58.

ALFARO, C. (1997): El tejido en época romana, Madrid, Arco Libros, 78 p.

ALFARO, C. (1999): "Más allá de la labor matronalis: aspectos del trabajo profesional femenino en el mundo antiguo", en: Saitabi, 49, 207-359. 
ALFARO, C. (2011): "La cité de Saiti/Saetabis et son aire d'influence: économie du territoire et production de tissus à l'époque ibéro-romaine", en: Alfaro, C., Brun, J.-P., Borgard, Ph., Pierobon Benoit, P. (Eds.), Purpureae Vestes III: Textiles y Tintes en la Ciudad antigua: Actas del III Symposium Internacional sobre Textiles y Tintes del Mediterráneo en el Mundo Antiguo (Nápoles, 13 al 15 de noviembre, 2008), Valencia, PUV, 55-68.

ALFARO, C. (2013a): "Purple and Aristocracy: color, blood and luxury as social identifiers in Antiquity”, en: Alfaro, C., Ortiz, J., Martínez, M. J. (Eds.), Luxury and Dress. Political power and appearance in the Roman Empire and its Provinces, Valencia, PUV, 75-98.

ALFARO, C. (2013b): "Betrachtungen zur iberischen Frauenkleidung", en: Tellenbach, M., Schulz, R., Wieczorek, A. (Eds.), Die Macht der Toga. DressCode im Römischen Weltreich, Regensburg, Schnell \& Steiner, 171-173.

ALFARO, C. (2015): "El tocado de la Dama de Baza y sus orígenes mediterráneos", en: Tiaras, diademas y tocados en las Culturas del Mediterráneo Antiguo: Simbolismo y Tecnología, Valencia.

ANDERSSON STRAND, E. (2010a): "Experimental Textile Archaeology", en: Andersson Strand, E., Gleba, M., Mannering, U., Munkholt, C., Ringgaard, M. (Eds.), North European Symposium for Archaeological Textiles X (NESAT X). Copenhagen, 13-18 May 2008, Oxford, Oxbow Books, 1-3.

ANDERSSON STRAND, E. (2010b): "The Basics of Textile Tools and Textile Technology: From fibre to fabric", en: Michel, C., Nosch, M.-L. (Eds.), Textile Terminologies in the Ancient Near East and Mediterranean from the third to the first millennia BC, Oxford, Oxbow Books, 10-22.

BELANOVÁ, T. y PIETA, K. (2007): "Discovery of a Unique Chamber Tomb in Poprad-Matejovce (Slovakia)", Archaeological Textiles Newsletter, 44, 18-20.

BIRLEY, R. E. (2009a): Vindolanda: A Roman Frontier Fort on Hadrian's Wall, Stroud, Amberley Publishing.

BIRLEY, A. R. (2009b): "Some writing tablets excavated at Vindolanda in 2001, 2002 and 2003", Zeitschrift für Papyrologie und Epigraphik, 170, 265-293.

BÖHME-SCHÖNBERGER, A. MITSCHKE, S. (2005): "Die römischen Stoffe aus Mainz, Baustelle Große Langgasse/Ecke Emmeranstraße”, Archaeological Textiles Newsletter, 41, 22-24.

BONFANTE, L. (2003): Etruscan Dress, Baltimore, JHU Press, 261 p.

BORG, B. (1996): Mumienporträts. Chronologie und kultureller Kontext, Maguncia, P. von Zabern, $262 \mathrm{p}$.

BOTTIGLIERI, A. (2002): La legislazione sul lusso nella Roma republicana, Nápoles, Edizioni scientifiche italiane, $198 \mathrm{p}$.

BOWMAN, A. K. (2003): Life and Letters on the Roman Frontier: Vindolanda and its People, Londres, British Museum Press, 167 p.

BOWMAN, A. K., THOMAS, J. D. (1994): The Vindolanda Writing Tablets (Tabulae Vindolandenses II), Londres, British Museum Press, 408 p.

BOWMAN, A. K., THOMAS, J. D., ADAMS, J. N. (2003): The Vindolanda Writing Tablets (Tabulae Vindolandenses III), Londres, British Museum Press, 208 p.

BOWMAN, A. K., THOMAS, J. D., TOMLIN, R. S. O. (2010): "The Vindolanda writing-tablets (Tabulae Vindolandenses IV, part 1)", Britannia, 41, 187-235.

CARROLL, M. (2010): Carroll, M.: "Götter, Sterbliche und ethnische Identität am Niederrhein: Die Aussage der römischen Weihedenkmäler", en: Mannheimer Geschichtsblätter 19, 2010, 97-106.

CASINOS, F. J. (2013): "Repression of Luxury in Rome: the specific case of Garments", en: C. Alfaro, J. Ortiz and $\mathrm{M}^{\mathrm{a}} \mathrm{J}$. Martínez (Eds.), Luxury and Dress. Political Power and Appearance in the Roman Empire and its Provinces, Valencia, PUV, 99-114.

DEMANT, I. (2011): "From Stone to textile: constructing the costume of the Dama de Baza", Archaeological Textiles Newsletter, 52, 37-40.

DEMANT, I. (2014): "From Stone to textile: the 'Dama de Baza", en: Alfaro, C., Tellenbach, M., Ortiz, J. (Eds.), Production and Trade of Textiles and Dyes in the Roman Empire and Neighnouring Regions, Valencia, PUV, 21-26. 
DROß-KRÜPE, K. (2011): Wolle - Weber - Wirtschaft. Die Textilproduktion der römischen Kaiserzeit im Spiegel der papyrologischen Überlieferung, Wiesbaden, Harrassowitz, 304 p.

ESPÉRANDIEU, E. (1907-1938): Recueil général des bas-reliefs, statues et bustes de la Gaule romaine, Paris, Imprimerie Nationale.

FERNÁNDEZ NIETO, F. J., MOLINA GÓMEZ, J. A. (2012): "Die Bedeutung von spezifischer Kleidung in römischen Kulten”, en: Schrenk, S., Vössing, K., Tellenbach, M. (Eds.), Kleidung und Identität in religiösen Kontexten der römischen Kaiserzeit, Regensburg, Schnell \& Steiner, 57-64.

FREI, K. M., FREI, R., MANNERING, U., GLEBA, M., NOSCH, M. L., LYNGSTRØM, H. (2009): "Provenance of ancient textiles - a pilot study evaluating the strontium isotope system in wool", Archaeometry, 51, 252-276.

GABELMANN, H. (1985): "Römische Kinder in Toga praetexta", Jahrbuch des deutschen archäologischen Instituts, 100, 497-541.

GARCÍA FERNÁNDEZ-ALBALAT, B. (2013): "La vestimenta de la heroización y la guerra en la cultura castreña”, en: Alfaro, C., Ortiz, J., Martínez, M. J. (Eds.), Luxury and Dress. Political power and appearance in the Roman Empire and its Provinces, Valencia, PUV, 51-74.

GLEBA, M., MANNERING, U. (Eds.) (2012): Textiles and Textile Production in Europe from Prehistory to $A D$ 400, Oxford, Oxbow Books, 512 p.

GOETTE, H. R. (1989): Studien zu römischen Togadarstellungen, Maguncia, Von Zabern, 207 p.

GOETTE, H. R. (2013): "Die römische 'Staatstracht' - toga, tunica und calcei” en: Tellenbach, M., Schulz, R., Wieczorek, A. (Eds.), Die Macht der Toga. DressCode im Römischen Weltreich, Regensburg, Schnell \& Steiner, 39-52.

GRÖMER, K. (2010): Prähistorische Textilkunst in Mitteleuropa. Geschichte des Handwerkes und Kleidung vor den Römern, Viena, Naturhistorisches Museum, 480 p.

HALD, M. y OLSEN, J. (1980): Ancient Danish textiles from bogs and burials: a comparative study of costume and Iron Age textiles, Copenhague, Museo Nacional de Dinamarca, 398 p.

HOSS, S. (2010): "Der Gürtel als Standeszeichen der römischen Soldaten", Mannheimer Geschichtsblätter, 19, 115-128.

HOUWING, J. H. (1883): De romanorum legibus sumptuariis, Leiden, S. C. van Doesburgh, 95 p.

MÖLLER-WIERING, S. (2007): "Italienische Mode im Stader Moor?", in Frank M. Andraschko, Barbara Kraus, Birte Meller (Hrsg.): Archäologie zwischen Befund und Rekonstruktion, Kovač, Hamburgo.

PARLASCA, K. (1966): Mumienporträts und verwandte Denkmäler, Wiesbaden, Steiner, 293 p.

PASZTÓKAI-SZEÖKE, J. (2011): "The mother shrinks, the child grows. What is it? The evidence of spinning implements in funerary context from the Roman province of Pannonia”, en: Alfaro, C., Martínez, M. J., Ortiz, J. (Eds.), Mujer y Vestimenta. Aspectos de la identidad femenina en la Antigüedad, Valencia, PUV, 125-140.

PRESEDO VELO, F. J. (1973): “La Dama de Baza”, Trabajos de Prehistoria, 30, 1, 151-216.

REINHOLD, M. (1970): History of Purple as a Status Symbol in Antiquity, Bruselas, Latomus, 75 p.

RICHTER, G. M. (1987): Handbook of Greek Art, Londres, Phaidon, 431 p.

RÖMER, C. (2013): "Was so in einem reichen Haus zu finden war", en: Tellenbach, M., Schulz, R., Wieczorek, A. (Eds.), Die Macht der Toga. DressCode im Römischen Weltreich, Regensburg, Schnell \& Steiner, 161-163.

ROTHE, U. (2009): Dress and Cultural Identity in the Rhine-Moselle Region of the Roman Empire, Oxford, Archaeopress, $179 \mathrm{p}$.

RUEDA, C. (2008): "Las imágenes de los santuarios de Cástulo: Los exvotos ibéricos en bronce de Collado de los Jardines (Santa Elena) y Los Altos del Sotillo (Castellar)", Paleohispanica, 8, 55-87.

RUEDA, C. (2011): Territorio, culto e iconografía en los santuarios iberos del Alto Guadalquivir (ss. IV a.n.e. - I d.n.e.), Jaén, Universidad de Jaén, 325 p. 
RUEDA, C. (2013): "New views on the analysis of dress. Ritual and prestige in Iberian Sanctuaries: preliminary results", en: Alfaro, C., Ortiz, J., Martínez, M. J. (Eds.), Luxury and Dress. Political power and appearance in the Roman Empire and its Provinces, Valencia, PUV, 31-50.

RUEDA, C. (2015): "The hairstyles and headdresses of the Iberian bronze ex-votos in the territory of Cástulo", en: Tiaras, diademas y tocados en las Culturas del Mediterráneo Antiguo: Simbolismo y Tecnología, Valencia, PUV.

SCHMIDT-COLINET, A. (1996): "East and West in Palmyrene Pattern Books", en: DirectorateGeneral of Antiquities and Museums (Ed.), Palmyra and the Silk Road: Special Issue documenting the Activities of the International Colloquium, Damasco, 417-423.

SCHMIDT-COLINET, A. (2009): "Nochmals zur Ikonographie zweier palmyrenischer Sarkophage”, en: Blömer, M., Facella, M., Winter, E. (Eds.), Lokale Identität im Römischen Nahen Osten. Kontexte und Perspektiven. Erträge der Tagung, Lokale Identität im Römischen Nahen Osten“ Münster 19.-21. April 2007, Stuttgart, Steiner, 223-234.

SCHMIDT-COLINET, A., STAUFFER, A., AL-AS'AD, K. (2000): Die Textilien aus Palmyra. Alte und neue Funde, Maguncia, Ph. von Zabern, $201 \mathrm{p}$.

SPEIDEL, M. A. (2009): Heer und Herrschaft im römischen Reich der hohen Kaiserzeit, Stuttgart, Steiner, $706 \mathrm{p}$.

STAUFFER, A. (2002): "I tessuti", en: von Eles, P. (Ed.), Guerriero e sacerdote. Autorità è comunità nell' età del ferro a Verucchio. La Tomba del Trono, Florencia, 192-219.

STAUFFER, A. (2004): "Early Etruscan Garments from Verucchio", Bulletin du liaison du C.I.E.T.A., 81, 15-20.

STAUFFER, A. (2007a): "Imports and exports of textiles in Roman Syria”, Topoi Suppl., 8, 357-373.

STAUFFER, A. (2007b): “Antike chinesische Textilien als Handelsgüter im Westen”, en: Kunstund Ausstellungshalle Bonn (Ed.), Unter der gelben Erde, Maguncia, 189-198.

TELLENBACH, M., SCHULZ, R., WIECZOREK, A. (2013): (Eds.), Die Macht der Toga. DressCode im Römischen Weltreich, Regensburg, Schnell \& Steiner, 171-173.

TZACHILI, I. (2013): "Webkunst und Kleiderproduktion als Tätigkeit der Frau im Griechenland der Römerzeit", en: Tellenbach, M., Schulz, R., Wieczorek, A. (Eds.), Die Macht der Toga. DressCode im Römischen Weltreich. (2013) Regensburg, Schnell \& Steiner, 115-119.

VON CARNAP-BORNHEIM, C., NOSCH, M.-L., GRUPE, G., MEKOTA, A.-M., SCHWEISSING, M. (2007): "Stable strontium isotopic ratios from archaeological organic remains from the Thorsberg peat bog", Rapid Communications in Mass Spectrometry, 21, 1541-1545.

VON HASE, F.-W. (2013): "Zur Kleidung im frühen Etrurien”, en: Tellenbach, M., Schulz, R., Wieczorek, A. (Eds.), Die Macht der Toga. DressCode im Römischen Weltreich, Regensburg, Schnell \& Steiner, 72-79.

WILD, J. P (2011): "Vindolanda and its textiles: Gavvo and his tosseae", en: Alfaro, C., Brun, J.-P., Borgard, Ph., Pierobon Benoit, P. (Eds.), Purpureae Vestes III: Textiles y Tintes en la Ciudad antigua: Actas del III Symposium Internacional sobre Textiles y Tintes del Mediterráneo en el Mundo Antiguo (Nápoles, 13 al 15 de noviembre, 2008), Valencia, PUV, 69-73.

WIPSZYCKA, E. (1965): L'industrie textile dans l'Égypte romaine, Varsovia, 167 p.

ZANKER, P. (1987): Augustus und die Macht der Bilder, Múnich, 368 p. 
